\title{
ACONTECIMIENTOS ANÓNIMOS, UN PROYECTO ARTÍSTICO SOBRE SOBRE LA PANTALLA CONTEMPORÁNEA
}

\author{
María Zarraga Llorens \\ Universitat Politècnica de València, Dpto. Escultura
}

\section{Resumen}

Reflexionar y teorizar sobre la realidad a través de un proyecto artístico que utiliza la fotografía, el fotomontaje, el tratamiento digital. Este es el objetivo de este texto, interpretar ciertos aspectos de las nuevas tecnologías a partir de la observación del entorno urbano. En concreto, destacamos el papel relevante, casi hegemónico de las pantallas de nuestros dispositivos y como observamos que influyen en nuestra actitud. En la actualidad estos elementos, las pantallas, se hacen imprescindibles en nuestra sociedad contemporánea y se convierten en extensiones de nuestro cerebro, que nos permiten permanecer constantemente comunicados e informados. A lo largo del texto relacionamos conceptos con el pensamiento de algunos teóricos de las nuevas tecnologías. A estas reflexiones se acompaña la descripción y las imágenes que ilustran el proceso de trabajo de nuestro propio proyecto artístico, en el que se ve a la pantalla protagonista como símbolo de nuestro tiempo.

\section{Palabras-clave: PANTALLA; FOTOGRAFÍA ESCENIFICADA; ACTITUD; HEGEMONÍA;} NUEVAS TECNOLOGÍAS

\section{ANONYMOUS AFFAIRS, AN ARTISTIC PROJECT ABOUT THE CONTEMPORARY SCREEN}

\section{Abstract}

Thinking over and considering about reality through an artistic project. Using photography, photomontage and digital tools. The aim of this text is to understand certain aspects from the new technologies, watching the urban context. Specifically we highlight the hegemonic and outstanding role of the screens, the electronic devices and the way these gadgets affect our everyday behavior. Nowadays, these elements, the screens, have become essentials in our contemporary society and they spread our brain, allowing us to keep constantly informed and communicated. All along the text, we relate concepts with the thought of certain experts of the new technologies. These considerations go along with the description and pictures from our own artistic work where the screen as main character became the symbol of our time.

Keywords: SCREEN; STAGED PHOTOGRAPHY; ATTITUD; HEGEMONY; NEW TECHNOLOGIES

\footnotetext{
Zarraga Llorens, María. 2016. “Acontecimientos anónimos, un proyecto artístico sobre sobre la pantalla contemporánea”. AusArt 4(1): pp-pp. 53-64 DOI: 10.1387/ausart.16678
}

\section{AUSART}


El artista japonés Hiroshi Sugimoto presentó en el año 1998 en nuestro país, una exposición en La Fundación La Caixa. Entre otros trabajos, presentaba una serie de obras fotográficas basadas en la documentación de antiguas salas cinematográficas norteamericanas, cuya particularidad era la presencia de las pantallas de cine, que ocupaban el centro de la fotografía.

La intención de Sugimoto era documentar y al mismo tiempo rendir homenaje a estos lugares amenazados por la destrucción y el declive del propio consumo del cine, que ha dejado paso con los años a otro tipo de usos. Sin embargo, estas fotografías tal y como estaban realizadas suponían toda una reflexión sobre el paso del tiempo y como este queda apresado en la película. Una reflexión sobre como el instante fotográfico congela y condensa el transcurrir del tiempo.

Como nos señalaba Hay Halpert al hablar de Sugimoto en el texto del catálogo de la exposición, "el artista comprime el tiempo en las imágenes en movimiento y simultáneamente lo dilata en la inmovilidad de la fotografía" (Hay Halpert 1998, 23).

La belleza de las imágenes de Sugimoto, reside en la simplicidad, en la visión de la pura luminosidad que desprenden las pantallas, de la nada, del vacío. "Para Sugimoto, el tiempo se encuentra simultáneamente condensado y dilatado en la pantalla. Hacer que la película, una sucesión de miles de imágenes individuales desemboque en una única imagen de blancura absoluta, es un acto de reducción" (25).

Por este motivo, esta serie de Sugimoto, nos sirve para iniciar este artículo y también como metáfora del hecho cotidiano de las pantallas con las que convivimos en nuestro día a día, en las que se proyectan cientos de imágenes y si se fundieran todas llegarían al blanco, convirtiéndose en luz absoluta, como un signo que demuestra la acumulación y negación. Un signo de nuestro mundo, donde el exceso nos empuja a no detenernos a leer y mirar con detalle, tal vez porque no da tiempo y hay que seguir consumiendo las imágenes e información que ininterrumpidamente proporcionan las pantallas de los dispositivos.

Nuestra percepción personal de los cambios que en los últimos diez años se han producido de forma vertiginosa con las nuevas tecnologías, nos indujo, por pura observación de lo que sucedía en los entornos urbanos, a comenzar un proyecto fotográfico basado en la pantalla como objeto protagonista. Se trataba de escenificar con fotomontajes aquellos ámbitos de trabajo y relación 
en los que las pantallas están presentes. Este proyecto cristalizó a lo largo de 2010 con una serie fotográfica titulada Acontecimientos anónimos porque en el fondo se trataba de insinuar como pese a la sobreabundancia informativa, la saturación de imágenes que acompañan el "decorado" de nuestras calles y allá por donde nos movemos, queda al final, un sentimiento de vacío, de desinformación. Por lo menos esta era nuestra motivación al crear estas imágenes. Y esa misma sensación es la que percibíamos en la contemplación de las obras de Sugimoto. Tras la acumulación, la nada.

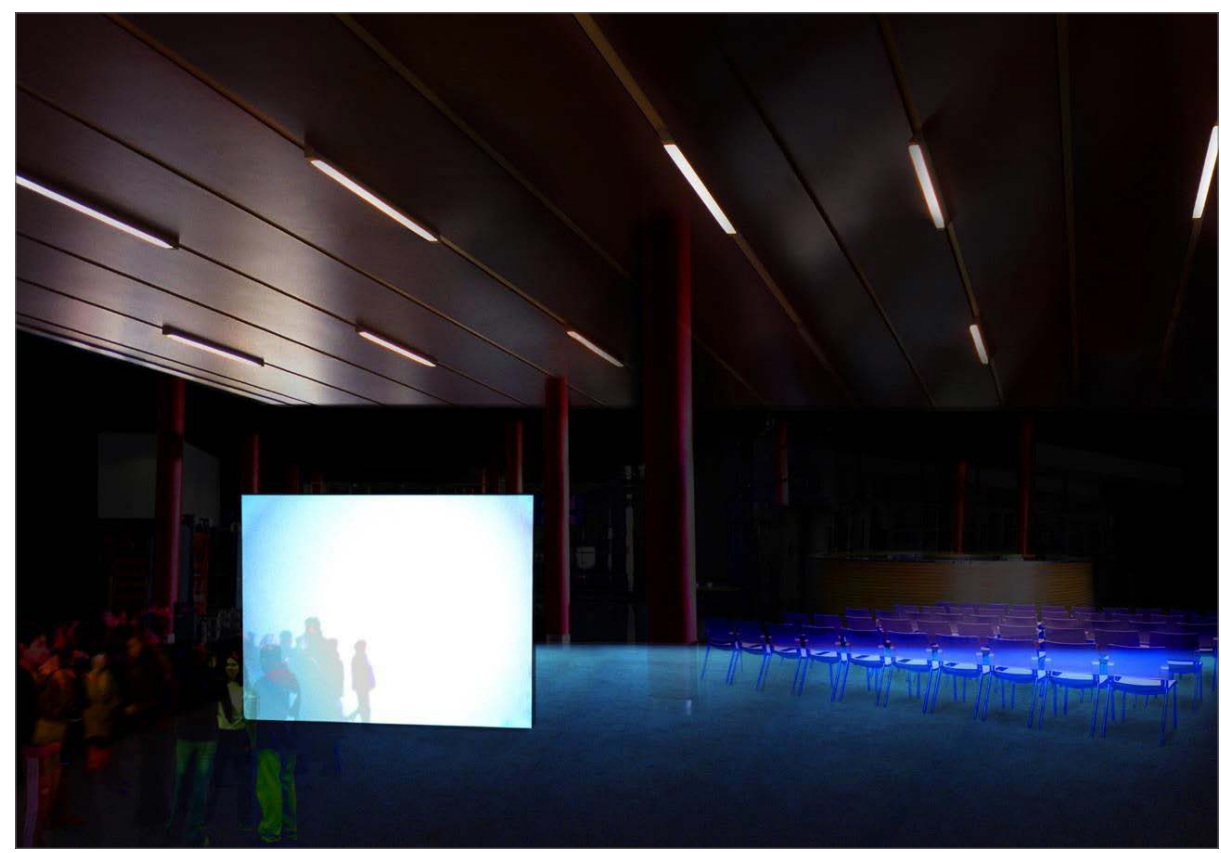

Fig.: 1. M. Zarraga. Acontecimientos anónimos 6, 2010.

Nuestro proyecto de Acontecimientos anónimos no se refería a ningún lugar concreto, eran espacios inventados, anónimos como indica el título, pero tenían como punto en común el tratarse de posibles espacios públicos, tierras de nadie, los no-lugares que define Marc Augé. (1992). Será a partir de estas obras cuando abrimos una pequeña reflexión sobre la pantalla como objeto cada vez más presente en nuestro devenir cotidiano. $Y$ tal vez la primera impresión que recibimos es negativa pese al beneficio que supone para la inmediatez y facilidad en las comunicaciones. Porque pese al derroche de posibilidades, las tablets, los móviles, los ordenadores, las pantallas que nos informan en la calle, en el metro en los aeropuertos, etc, parece que el indivi- 
duo se aísla cada vez más en su propia burbuja. Ya anunciaba Lev Manovich ([2001] 2005, 167) que "a nuestro alrededor todos son signos de creciente movilidad y de la miniaturización de los aparatos de comunicación: desde los móviles a las agendas electrónica, pasando por los buscapersonas y los portátiles, los teléfonos y los relojes que permiten navegar por la red (...)“.

No hay más que reconocer el gesto ya común de los transeúntes mirando hacia su móvil, con la cabeza inclinada, mientras caminan por la calle. No se mira el paisaje, no se mira por la ventana del autobús, no se mira al vecino del asiento de enfrente. Se mira el móvil.

Tal vez por esto la pantalla se ha vuelto cotidiana, fácil, indispensable.

Como anticipaba Manovich, vivimos en la sociedad de la pantalla y éstas están por todas partes, en nuestras casas, en las oficinas, en la calle. "Dinámica, en tiempo real o interactiva, una pantalla sigue siendo una pantalla. Interactividad, simulación y telepresencia: igual que sucedía hace siglos, seguimos mirando una superficie plana y rectangular, que existe en el espacio de nuestro cuerpo y que actúa como una ventana a otro espacio. No hemos dejado aún la era de la pantalla". ([2001] 2005, 168). El argumento de este autor nos recuerda que ya los pintores en el Renacimiento inventaron un artilugio cuadrado o panorámico que era un filtro que seleccionaba la visión más óptima para luego trasladarla al lienzo. Para nosotros la coincidencia con el objeto pantalla actual, comienza con el formato apaisado aceptado de este invento y como lo puede ser también el visor de una cámara, es decir el interfaz por el que miramos y decidimos quedarnos con un trozo del mundo. Y la pantalla contemporánea nos devuelve la selección de imágenes del mundo que debemos consumir.

Juan Carlos Pérez Jiménez, en un artículo sobre la revolución digital, cita a Peter Weibel, profesor y teórico de las nuevas tecnologías, quien afirma que la máquina comienza a ser problemática cuando entra en el campo de la cultura. "La cosa cambia cuando las máquinas entran en el terreno de la creatividad, el arte o las ideas. Cuando comienzan a funcionar como prótesis no de nuestro cuerpo, sino de nuestra mente, se produce un rechazo mucho más profundo, una reacción alérgica a la tecnología como amenaza. (...) La sensación de amenaza que provoca la tecnología en nuestro self evidencia la fragilidad con la que vivimos nuestra propia identidad". (Pérez Jiménez 1998, 129).

Pero frente a la visión catastrofista, no podemos ocultar la capacidad benéfica y redentora de las nuevas tecnologías y el poder ilusionante que generan con 
cada nuevo avance y mejora. Aunque de nuevo nos envuelve la duda al pensar si no será solo el deseo de cambio y posesión del último aparato del mercado, basado en el envoltorio y glamour que desprende cada nuevo modelo y no tanto la posible mejora que declara la publicidad. Como sigue apuntando J. C. Pérez Jiménez (1998, 129), "estamos hipnotizados por las imágenes y la ansiedad que nos inocula la contemplación de las pantallas no se equilibra con lo que nos aporta la realidad".

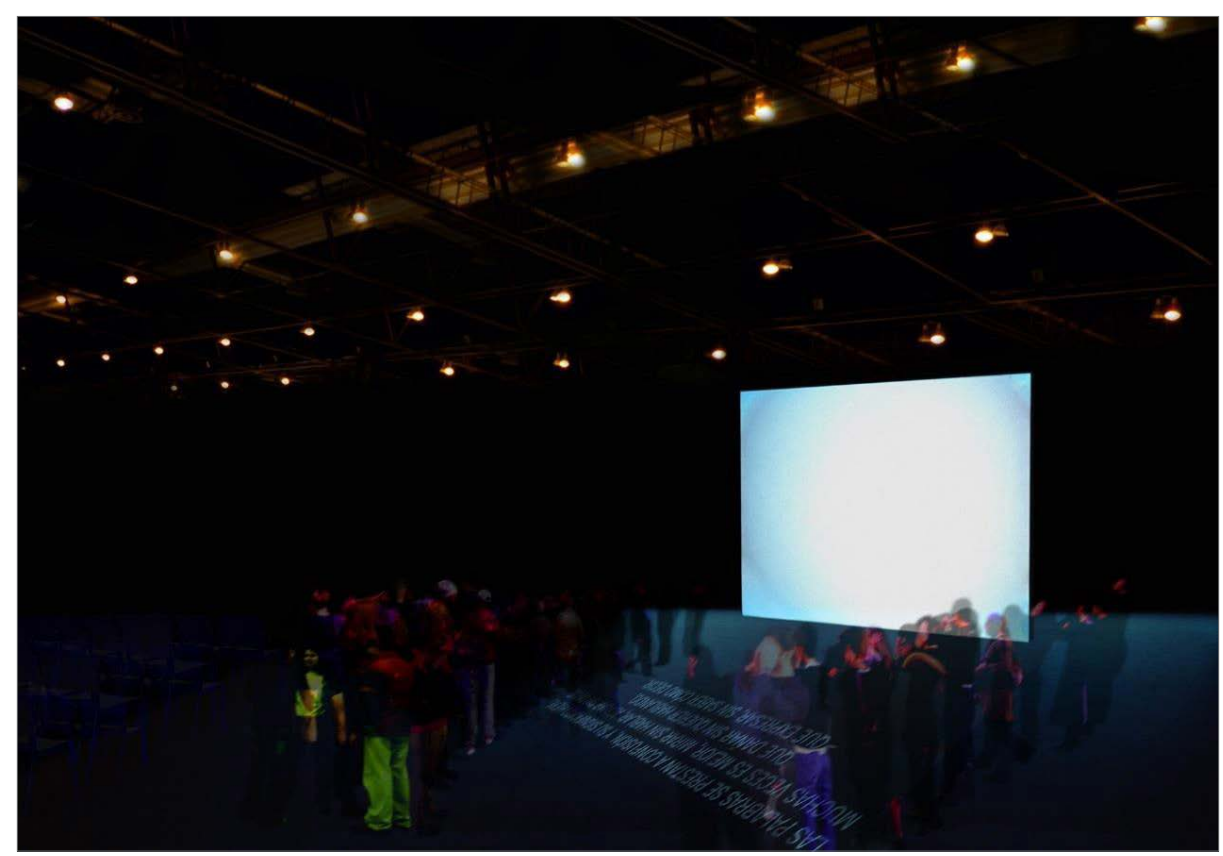

Fig. 2. M. Zarraga. Acontecimientos anónimos 7, 2010

Desde luego, no podemos obviar esa capacidad absorbente cuando pensamos en los videojuegos y como hipnotizan a los más jóvenes mostrando ficciones cada vez más logradas a través de la pantalla. Los niños de hoy, "devoran" pantallas en su tiempo de ocio.

Podemos hablar de ventanas, podemos hablar de cámaras que vigilan nuestros movimientos, podemos hablar de pantallas que a su vez están conectadas con cámaras que a su vez acaban en pantallas y monitores que alguien controla. Toda una red de observación y control se teje a nuestro alrededor, sin que podamos controlarlo y lo que es peor, identificarlo. 
Podemos hablar de pantallas de dispositivos móviles, de pantallas de ordenadores que nos devuelven información pero que son intermediarios de comunicación con el otro. Este aspecto nos parece muy interesante. Disminuye la comunicación cara a cara, cada vez es más pobre o complicada pero aumenta exponencialmente la comunicación que se establece a través de la pantalla mediadora. El logro de las redes sociales. La pantalla se coloca en medio, ocupando el papel de intermediaria en las relaciones a distancia.

Podemos hablar de la pantalla que poseen nuestros dispositivos y que ejerce de artefacto de encuadre, de elemento de captura de nuestras instantáneas. Los dispositivos móviles, aunque poseen sus pequeñas cámaras, dan la impresión de que es la pantalla la que dispara y captura la imagen. También en este espacio, el de la fotografía, se han ido adueñando del terreno.

Como explica Jonathan Crary ([1990] 2008, 16), "la mayor parte de las funciones históricamente importantes del ojo humano están siendo suplantadas por prácticas en las que las imágenes visuales ya no remiten en absoluto a la posición del observador en un mundo "real", percibido ópticamente".

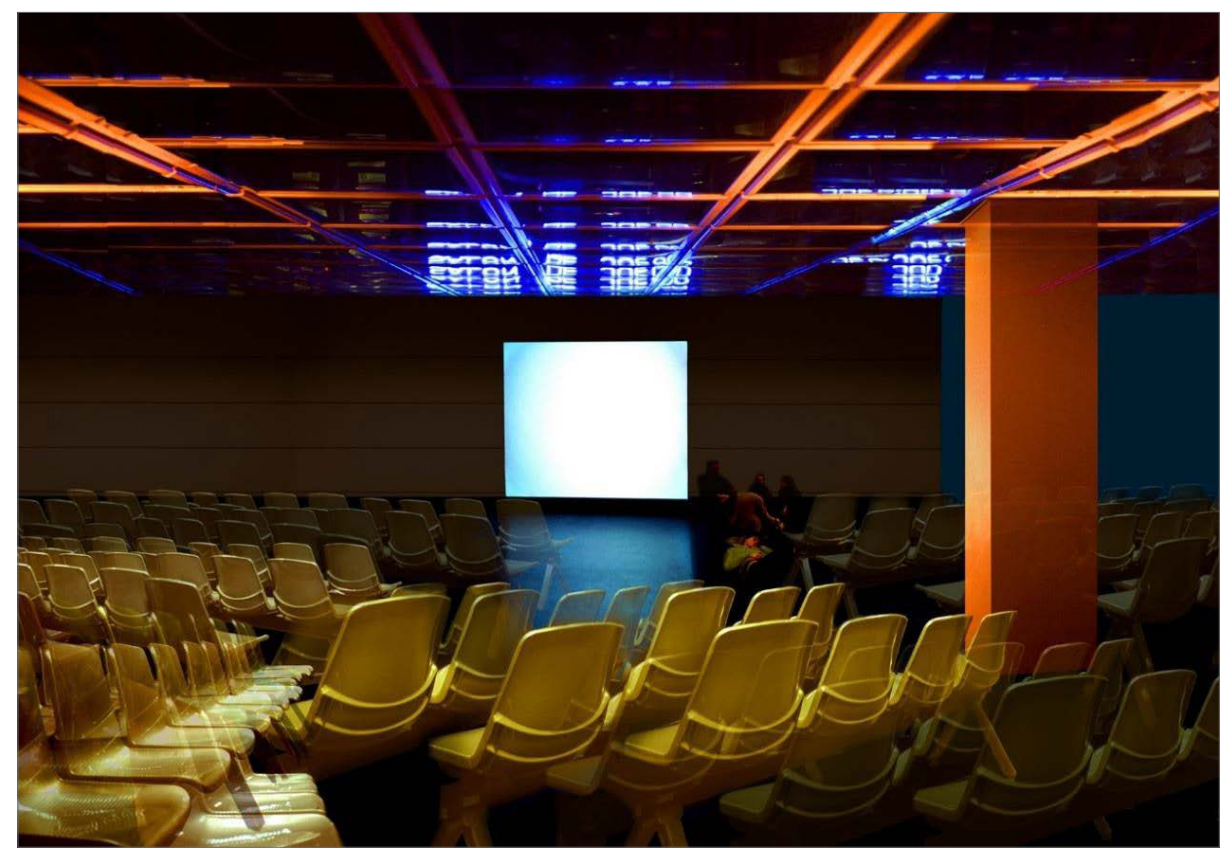

Fig.3. M. Zarraga. Acontecimientos anónimos 2, 2010 
A propósito de alguno de estos trabajos donde colocamos pantallas que rodean a grupos de gente, Jonathan Crary ([1990] 2008, 37) nos recuerda el pensamiento de Foucault reflejado en su libro Vigilar y castigar: "Nuestra sociedad no es una sociedad del espectáculo sino de la vigilancia...No nos encontramos ni en el anfiteatro ni en el escenario, sino en la máquina panóptica". Este comentario nos sirve para ilustrar nuestras composiciones, para tratar de explicar ese acercamiento de la pantalla de forma impositiva, del sentimiento de ojo que nos vigila.

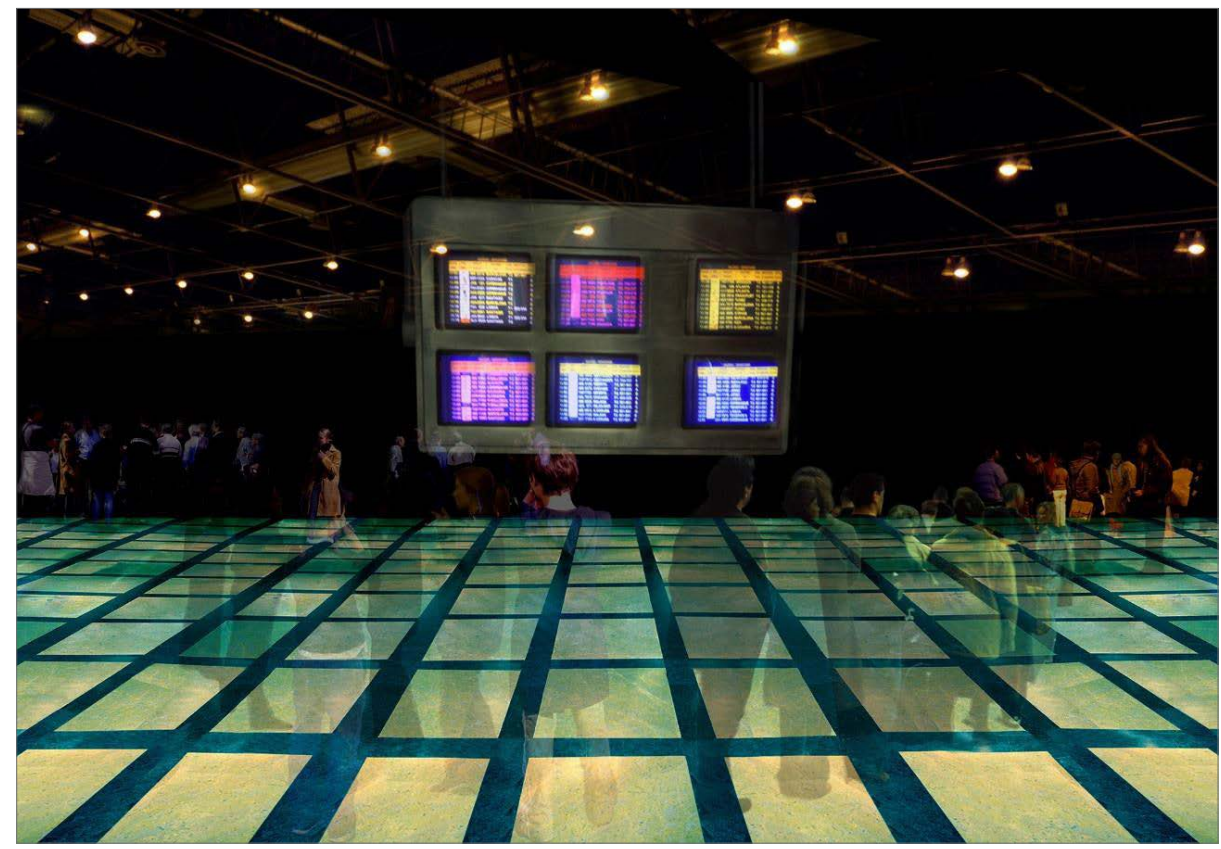

Fig. 4. M. Zarraga. Acontecimientos anónimos 4, 2010

Recordando los experimentos de científicos como Fechner, que alrededor de 1840, se aplicaron en la medición de las experiencias sensoriales y su influencia en nuestro cerebro (Crary [1990] 2008, 190-1), nos preguntamos de qué forma en la actualidad los modernos dispositivos actúan sobre nuestra mente. Al igual que los estudios que se realizaron sobre la postimagen retiniana, podríamos comparar de qué forma persiste la imagen, si genera confusión, entre lo grabado en nuestra memoria y lo que estamos viendo repetitivamente. Podríamos pensar entonces, que ya no es el ojo el que dicta las percepciones sino la pantalla, convertida en nuevo modelo perceptivo. Volviendo a nuestras fotografías, la idea era crear escenarios de cierta confusión visual, donde las capas de personajes, pantallas y otros elementos de la composición quedan 
entrelazadas. Pretendíamos mostrar de alguna manera, este sentimiento caótico de la multipantalla.

Es fascinante comprobar la capacidad de adaptación de nuestro cerebro y como debido a la sofisticación de los tiempos que vivimos somos capaces de dividir nuestra atención y atender al fenómeno de la multipantalla, algo que asombraría a dos generaciones anteriores a la nuestra. Así pues, las nuevas tecnologías nos condicionan y nos vamos acostumbrando a nuevos comportamientos, vamos adaptando nuestro cerebro a los nuevos fenómenos asociativos, habituamos a nuestra mente a seleccionar, archivar y extraer lo fundamental.

Como señala Gonzalo Abril, el uso de estereotipos, de frases tópicas de la drogodependencia, podría definir las nuevas actitudes que se derivan del uso de las nuevas tecnologías de la comunicación, somos "teleadictos", "enganchados" a videojuegos, internet o móviles. "La noción de "enganche" si no viniera tan moralizada, sería una metáfora mecánica aceptable para la interfaz tecnológica", pero también cabe decir que "pese a los estereotipos el receptor postmoderno típico no es una víctima abnegada de la alienación y el sometimiento al "Gran Hermano" (Abril 1998, 170). Se diría que hemos aprendido a "leer" en todo este proceso, nos hemos acostumbrado a reconstruir los mensajes, pese al zapping continuo o como señala Martín Prada (2012, 94), el escenario es alienante: "el abandonarse activo del espectador que nos sitúa en el papel de auténticos "autómatas espirituales".

Tal y como vivimos la actualidad no se puede predecir hacia donde nos conducen todos los cambios e incorporaciones con los nuevos dispositivos. Con el trabajo que presentamos, hemos intentado plantear este escenario confuso, de mezclas. Impredecible.

Tras esta introducción en la que hemos tratado de explicar nuestra opinión, dudas y percepción sobre las actitudes y los dispositivos, se puede entender mejor el trabajo artístico que planteamos. Para realizar unos fotomontajes que muestren esta realidad discontinua a partir de las pantallas que nos rodean, nos planteamos en primer lugar fotografiar las calles, estaciones de metro, salas de espera, entre otros lugares públicos donde las pantallas se ven con frecuencia. Comenzamos recopilando fotografías de espacios grandes, vacíos, donde se observara la arquitectura, paredes, suelos. $Y$ en segundo lugar, utilizamos imágenes de personas, mobiliario, luces y otros elementos, como atrezzo para estas escenificaciones. 

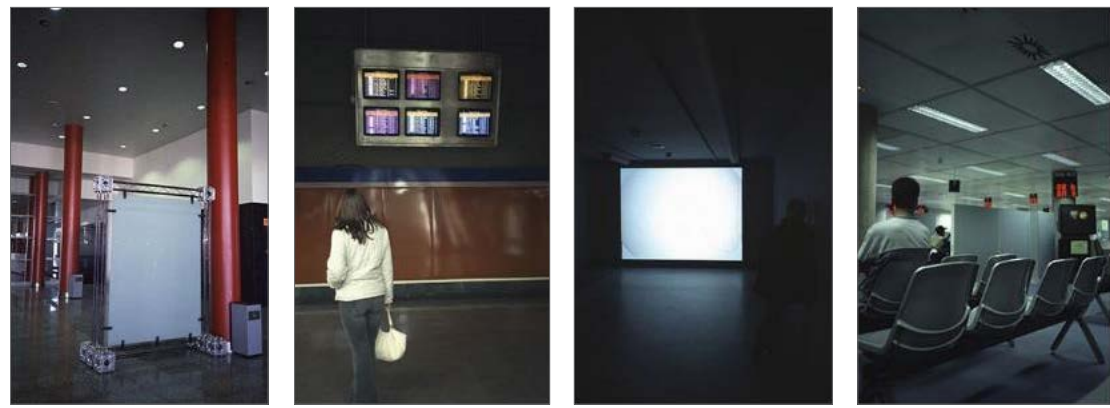

Fig. 5. Fotografía originales de diversos espacios. M. Zárraga. 2010-2015

El proceso comienza planteando un espacio de trabajo desde Photoshop C6, utilizando un lienzo en blanco donde vamos incorporando los elementos que nos interesan, ya sea un suelo, unas luces o unas sillas, para luego añadir, gente y pantallas. Según el material de que disponemos, tratamos de crear una composición que por su escala y por el punto de vista central, con profundidad de campo, de la sensación de espacio real.
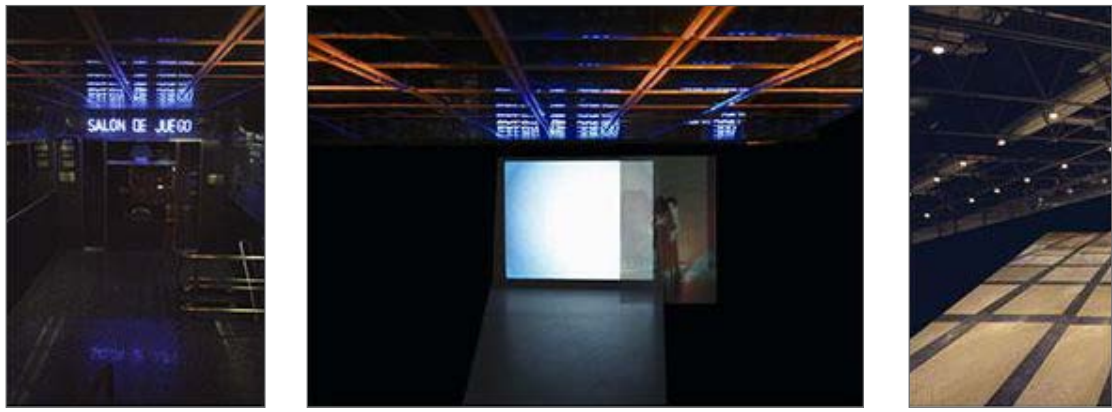

Fig. 6. Fotografía original a la izquierda y bocetos con elementos recortados

Photoshop nos permite trabajar con gran cantidad de capas de archivos, jugando con las superposiciones, opacidades y que vamos finalmente acoplando. Esta metodología de trabajo nos redirige inevitablemente al concepto que origina el proyecto. El caos, las superposiciones o la multitud de pantallas.

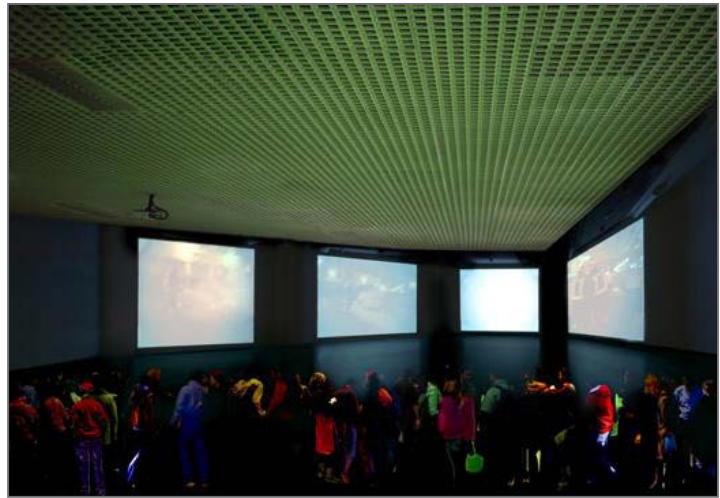

Fig. 7. María Zárraga, Acontecimientos anónimos 3, 2010 


\section{CONCLUSIONES SOBRE EL PROYECTO ARTÍSTICO}

Desde el punto de vista de la composición esta colección de fotografías sigue el mismo esquema. La representación de la pantalla debía aparecer siempre bien iluminada, junto con la representación de la figura humana. La relación de tamaño entre personas y pantallas es desigual y éstas adquieren un tamaño considerable, generalmente en el centro de la imagen. Así como la pantalla se ve claramente en todas las composiciones, el elemento humano sin embargo está colocado frente o alrededor de la pantalla y utilizamos en este caso la opción de jugar con la transparencia, quedando los personajes en segundo plano de importancia, restándoles el papel protagonista.

En definitiva, toda la serie reflexiona sobre la imagen icónica de la pantalla, así como el juego de volúmenes, como tótems, donde la imagen final que ofrece cada fotografía pretendíamos que se convirtiera en una pantalla que encierra otra pantalla.

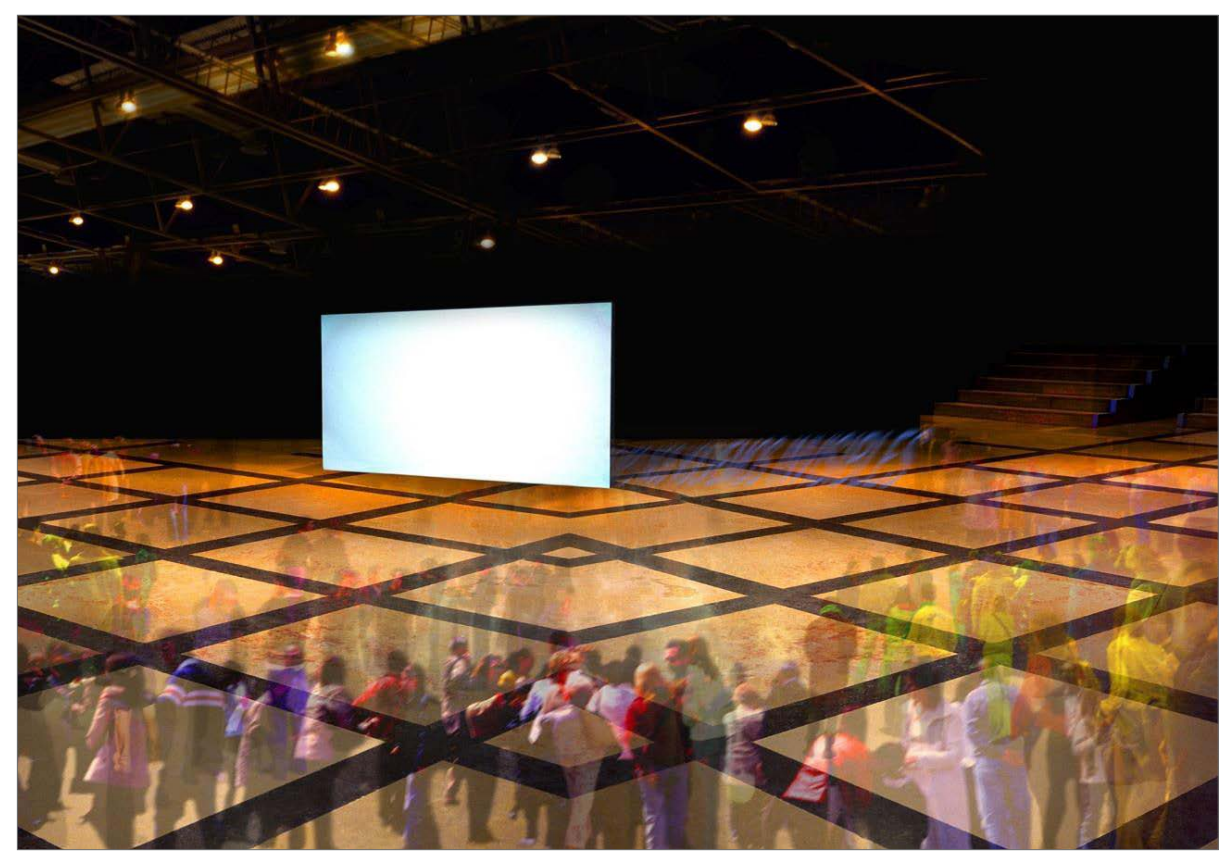

Fig. 8. María Zárraga, Acontecimientos anónimos 8, 2010 
La intención de cada composición era cuestionar la omnipresencia de todo tipo de pantallas, la multiplicidad de pantallas interpretando en clave de fotografía estas nuevas escenografías urbanas.

\section{CONCLUSIÓN FINAL}

El proyecto artístico, que comenzamos hace seis años, era por así decirlo una reflexión plástica, intuitiva, sobre los nuevos comportamientos que empezaban a tomar forma en el paisaje urbano. En la actualidad en 2016, retomamos esta reflexión con el punto de partida de un proyecto plástico, que fue el origen para conceptualizar sobre el tema de las pantallas.

Una vez terminado el proyecto sobre la representación del objeto, dónde como explicamos unas líneas más arriba elegíamos una representación de la pantalla y su multiplicidad, sin entrar en más consideraciones, en este artículo podemos a modo de conclusión concretar algunas ideas.

Diremos que al igual que la modernidad impuso un cambio de paradigma en la aproximación visual, en nuestra actualidad creemos que estos dispositivos, emitiendo imágenes, información y luz continua, están tan presentes que influyen en nuestra forma de mirar y crean nuevas temporalidades, velocidades y experiencias. Es decir, un proceso inevitable propio del progreso humano.

Es incuestionable la revolución que han supuesto la TIC y los beneficios que suponen en el ámbito de la educación, el ocio, las comunicaciones, el progreso en el lenguaje audiovisual, los cambios en las formas narrativas, etc. Con este artículo no pretendíamos cuestionar estas aportaciones, ni entrar en un estudio sociológico, ni aplicar una metodología cuantitativa. Nuestro trabajo interpretaba algunos signos hoy consolidados en los comportamientos de nuestra sociedad contemporánea, como la transformación del paisaje urbano, las pantallas que nos rodean por todas partes y donde las personas estamos absorbidas mirando nuestras pantallas móviles.

No podemos cuestionar ni las nuevas escenografías, ni especular sobre los nuevos hábitos de comunicación en nuestra sociedad contemporánea, pero sí dejar el interrogante abierto a partir de la práctica artística, sobre las nuevas 
actitudes, en detrimento de antiguos hábitos. La observación, mirar a nuestro alrededor. Entre otros.

En el apartado donde si podemos concluir sin arriesgar, es en la comprobación de que el arte sigue funcionado como una herramienta útil, necesaria, para poder opinar de forma paralela sobre los cambios que nos sobrevienen.

\section{Referencias Bibliográficas}

Abril Curto, Gonzalo. 1998. "Sujetos, interfaces, texturas". En "La revolución digital: Individuo y colectividad en el ciberespacio", número monográfico, Revista de Occidente 206

Augé, Marc. (1992) 1998. Los "no lugares" espacios del anonimato: Una antropología de la sobremodernidad. Traducción, Margarita N. Mizraji. Barcelona: Gedisa

Crary, Jonathan. (1990) 2008. Las técnicas del observador: Visión y modernidad en el siglo XIX. Tradución Fernando López García. Murcia: Cendeac

Hay Halpert, Peter. (1994) 1998. Las pantallas vacías de Hiroshi Sugimoto [The black sreens of Hiroshi Sugimoto]. En Sugimoto [catálogo exposición], 22-7. Barcelona: Fundación La Caixa [Texto original: Artpress 196 (nov. 1994)]

Manovich, Lev. (2001) 2005. El lenguaje de los nuevos medios de comunicación. Traducción de Óscar Fontrodona. Barcelona: Paidós

Martín Prada, Juan. 2012. Otro tiempo para el arte. Cuestiones y comentarios sobre el arte actual, Valencia: Sendemá

Pérez Jiménez, Juan Carlos. 1998. "Entre la utopía y la paranoia". En "La revolución digital: Individuo y colectividad en el ciberespacio", número monográfico, Revista de Occidente 206 